\title{
META-ANALYSIS: EFFECT OF ARTEMETHER LUMEFANTRINE ON MALARIA STATUS IN PREGNANT WOMEN
}

\author{
Siti Nur Hanifah'), Uki Retno Budihastuti²), Eti Poncorini Pamungkasari3) \\ 1)Masters Program in Public Health, Universitas Sebelas Maret \\ 2) Department of Obstetrics and Gynecology, Dr. Moewardi Hospital, Surakarta \\ 3)Faculty of Medicine, Universitas Sebelas Maret
}

\begin{abstract}
Background: Artemisinin-based combination therapies are now the recommended first-line treatment of falciparum malaria globally, because they rapidly decrease parasitemia, hasten recovery, and reduce chances of development of drug resistance. It also recommended by the World Health Organization to treat uncomplicated falciparum malaria during the second and third trimesters of pregnancy, and quinine plus clindamycin during the first trimester This study aimed to explore effect of Artemether lumefantrine on malaria status in pregnant women using meta-analysis.

Subjects and Method: A systematic review and meta analysis was conducted by collecting articles from PubMed, ScienceDirect, and Google Scholar databases. The determination of selected articles based on eligible criteria using PICO: (1) Population= pregnant women, (2) Intervention= Artemether lumefantrine, (3) Comparison= Dihydroartemisinin-piperaquine, and (4) Outcome = malaria. Keywords used "Artemether Lumefantrine" or "AL" or "Dihydroartemisinin-piperaquine" or "malaria" and "pregnant women". The inclusion criteria were full text, randomized controlled trial, and published from 2016 to 2021. The articles were collected by PRISMA flow diagram. The selected articles were quantitatively assessed using Review Manager 5.3.

Results: A random effect model $\left(\mathrm{I}^{2}=97 \%\right)$ involved 5 studies from sub-Saharan Africa, Thailand-Myanmar, and United states. This study found that Artemether lumefantrine increased recovery from malaria in pregnant women than Dihydroartemisininpiperaquine $(\mathrm{RR}=1.10 ; 95 \% \mathrm{CI}=1.07$ to $1.13 ; \mathrm{p}<0.001)$.

Conclusion: Artemether lumefantrine consumtion increases rcovery from malaria in pregnant women than Dihydroartemisinin-piperaquine.
\end{abstract}

Keywords: Artemether lumefantrine, malaria, pregnant women

Correspondence:

Siti Nur Hanifah. Masters Program in Public Health, Universitas Sebelas Maret. Jl. Ir. Sutami 36A, Surakarta 57126, Central Java. Email: sitinurhanifah21@yahoo.com. Mobile: 085204219736. 